\title{
"Determinants of organizational citizenship behavior: A case study of sub-contracting organizations, Islamabad. Pakistan”
}

\begin{abstract}
Saqib Shahzad ${ }^{1}$, Professor Dr. Jehanzeb²
Abstract

The aim of this research study was to find out the impact of organizational commitment and job satisfaction on organizational citizenship behavior. Organizational commitment was defined as the connection of an employee with the organization, where job satisfaction was defined as the pleasurable state of an employee in the organization and organizational citizenship behavior was defined as the discretionary behavior of employees not formally recognized by the formal reward system. The population of subcontracted employees was 511 for three sub-contracting employees. The sample size was 300 as 300 questionnaires were distributed among the employees 223 questionnaires were returned forming a response rate of $74.3 \%$. The results of the study showed that organizational commitment was found to have significant impact on organizational citizenship behavior and job satisfaction was also found to have significant impact on organizational citizenship behavior.
\end{abstract} behavior

Keywords: organizational commitment, job satisfaction, organizational citizenship

\section{Introduction}

In today's dynamic corporate world the employers are keenly interested in employees' behavior. They firmly believe that the positive behavior of employees would give them good results in shape of productivity that ultimately would lead to high profitability which in turn would increase market share of the respective organization. Now behavior only with respect to job or productivity is not the sole dimension, the employees need to have good and polite behaviors with their colleagues and also with their supervisors just to ensure that all the operations of the organization run smoothly. In connection to these behaviors one very important of organizational behavior is the organizational citizenship behavior (OCB). OCB is relatively new concept on the face of organizational behavior. It was 1990s that this concept formally came on the horizon of organizational behavior (OB) and still is in continuation at a steady rate towards the maturity. As per the definition of lambert (2006), organizational citizenship behavior is the behavior that (i) goes over the limit of basic requirements of the

1 PhD Student, Institute of Management sciences, Peshawar. Lecturer, City University of Science and Information Technology

2 Head, Management Sciences Department. City University of Science and information technology 
job (fulfills the limits and goes beyond them), (ii) is to a large degree discretionary and (iii) is beneficial to the organization.

Organ (1988) first gave the definition of OCB that, the discretionary behavior of an individual employee not directly recognized by formal reward system and such behavior collectively promotes the effective functioning of the organization. OCB is a type of behavior that is exhibited by employees of the organization as an extra role behavior rather than in role behavior. The definition of Organ has put it clear that there is no rule in organizations to force citizenship behavior on employees, because if the organization sets up rules for such behavior then the discretion of employees would no longer exist and the employees will have to show such behavior regardless of their will. Researchers have argued that employees exhibiting OCB assist in the effective functioning of the organization and reflect the same image like the citizen of a city who works for the betterment of the city, so employees exhibiting citizenship behavior are expected to work for the betterment of the organization.

There are two dimensions of OCB. Organizational Citizenship Behavior towards Individuals (OCBI) and Organizational Citizenship Behavior towards Organization $(\mathrm{OCBO})$. OCBI are individual directed behaviors comprising of altruism and courtesy and $\mathrm{OCBO}$ are organization directed behaviors comprising of civic virtue, conscientiousness and sportsmanship. All these constitute as the five antecedents of $\mathrm{OCB}$ throughout the literature and hence collectively represent OCB.

Now when there is discussion of OCB the researchers are interested to find out that what determines this type of behaviors? In connection to this paper has talked about the determinants of citizenship behavior. There can be so many determinants but for the sake of simplicity the author has focused on only three factors through which the citizenship behavior can be determined. One determinant is job satisfaction. Through the literature it has been discussed that satisfied employees are usually more productive employees. Job satisfaction has been found to have positive association with organizational citizenship behavior (Ulku \& Serap, 2009). They have further stated in their research that higher the satisfaction higher will be the level of citizenship behavior of an employee in the organization. Zirgham (2009) has reported that altruism had significant and positive impact on job satisfaction. Since altruism is a measure of citizenship behavior so ultimately job satisfaction had significant and positive impact on OCB.

The second determinant that has been taken by the author is Organizational Commitment (OC). Now it is worthy of noticing that the more employees show commitment towards organization higher would be their citizenship behavior. Through the literature it has been found that organizational commitment has been found to 
have positive impact on job performance of employees. Zia and Riaz (2007) have stated that organizational commitment was found to have positive association with job performance and behavior of employees. So the employees more inclined towards organizational commitment the higher was their job performance and hence had a positive impact on their good behavior.

This research paper has discussed the Organizational citizenship behavior with the determinants being job satisfaction and organizational commitment. There has been enough literature on these measures but no research paper has been found that has discussed OCB with two determinants job satisfaction and organizational commitment together. So this up to my best knowledge is the first effort and the notable point is that this research has been conducted on sub-contractual employees. These are those employees who work for the parent company but are actually paid by their contracting organizations. The need for such research aroused and motivated the researcher as the organizations are now continuously trying to outsource their operations or activities. So in this regard organizations outsource their activities and then those activities are performed by the contracted employees. The objectives of this paper are as follows.

- To determine the impact of job satisfaction on organizational citizenship behavior.

- To examine the impact of organizational commitment on organizational citizenship behavior.

\section{Research Questions}

- What is the effect of job satisfaction on organizational citizenship behavior of subcontracted employees?

- What is the effect of organizational commitment on organizational citizenship behavior of subcontracted employees

\section{Literature Review}

\section{Organizational Citizenship Behavior (OCB)}

Organizational Citizenship Behavior (OCB) is a unique aspect of individual activity i.e. it is an extra role behavior that is formally recognized by the reward system that's why this is discretionary behavior. Organizational citizenship behavior describes the actions in which employees go above and beyond their prescribed role requirement. Such type of behavior is totally based on volunteerism from employees. In service providing organizations HRM practices have been found to have positive 
effects on organizational citizenship behavior through high job satisfaction (Terasa $\&$ Jose, 2007). Further in the study it has been found out that one probability could be that more the employees will secure higher would be their citizenship behavior. Organizational trust was found to have positive effect on conscientiousness, civic virtue and altruism (Serap \& Ulku, 2009). Trust was further categorized in (trust in managers, trust in organization and trust in coworkers). The more the employees have shown trust the higher was their satisfaction level and hence their inclination towards the citizenship behavior increased.

Armenio and Miguel (2009) have identified in their study that interactional justice was found to have significant impact on organizational citizenship behavior. Interactional was further measured by two facets i.e. interpersonal and informational justice. Interpersonal is one that had significant impact on OCB, in other words it can be said that interpersonal justice significantly predicted the citizenship behavior. Antecedents (altruism, conscientiousness and civic virtue) of organizational citizenship behavior (OCB) were found to have significant impact on citizenship bchavior (Ali, Shahzad, Bukhari \& Bashir, 2009). The groups showing citizenship behavior had positive effect on the effective performance of the group (Sevi, 2009). The more the groups have put up effort the better the consequences of group performance were observed. Procedural justice was found to have positive effect on the citizenship behavior, in this relationship commitment played the role of mediator (James et al., 2008). Leader member exchange (LMX) relations were also found to have significant impact on the citizenship behavior (Kanika, 2006). In this study procedural justice fully mediated the relationship between perceived contribution of LMX and OCB. Ethical behavior was found to have significant and positive effect on citizenship behavior (Tammy, Martha \& Thomas, 2006). High level of ethical behavior had led to higher level of OCB.

Organizational citizenship behavior was positively affected by collectivism and trust (Chein, 2007). Elizbeth (1996) found in her stud that service quality and specific HRM practices had positive effect on organizational citizenship behavior. Specific HRM practices were found useful in encouraging employees to show citizenship behaviors. Organizational citizenship behavior was positively related to the wok group performance (Podsakoff, Ahearne \& Mackenzie, 1997). The higher the work group performance has increased the productivity of the organization. According to the study of Seth and Simo (2005) the perception of safety had positive effect on citizenship behavior. The employees who had positive perception about the safety have been actively engaged in citizenship behavior. 


\section{Organizational Commitment (OC)}

Organizational commitment (OC) has been considered as one of the very important phenomena in explaining the behavior of employees. Through commitment an employee remains bonded with the respective organization. Organizational commitment was found to have positive effect on job performance and behavior of an employee (Zia \& Riaz, 2007). The more the employees exhibited positive behaviors the higher was their commitment level. In respect to turnover behaviors of employees the organizational commitment was found to have negative effect (Fern \& Kharti, 2001). Trust in supervisors and management of organization was found to have positive effect on commitment level of employees (Ozag, 2006). The higher trust in management has reduced the perception of threat and harm in the minds of employees and thus has increased the commitment level of employees. The employees having permanent status in their work has shown higher organizational commitment in comparison to the non-permanent or contractual workers, there a positive association found between job satisfaction and organizational commitment (Stephen \& David, 2006).

According to the study of Martha, Thomas and Tammy (2006) distributive and procedural justice were found to have significant impact on organizational commitment. Where commitment has significant effect on ethical behavior of employees. Organizational commitment was found to negative effect on turnover intentions of IT professionals in Pakistan (Rehman, Naqvi \& Ramay, 2008). The employees of IT industry of Pakistan showed low intensions to leave the organization hence they showed higher organizational commitment.

Organizational was further measured by three facets i.e. Affective Commitment (AC), Continuance Commitment (CC) and Normative Commitment (NC). Affective commitment is defined as the employee's positive emotional attachment to the organization. Affective Commitment refers to the employee's perceptions of their emotional attachment to or identification with their organization (Williams, 2004). Affective commitment had significant effect on job performance of employees ( $\mathrm{Zia}$ $\&$ Riaz, 2005). According to the study of Clarke (2006) affective commitment had significant impact on performance of employees.

Continuance Commitment (CC) has been defined as not leaving the organization and continuing with the same organization keeping in view the cost of leaving associated with it. Continuance commitment had significant effect on job performance of employees (Riaz \& Zia, 2005). The statistically significant association was found between perception of trust on supervisors and coworkers with continuance commitment (Ozag, 2002). The increased level of trust especially trust on management had significant effect on continuance commitment. Continuance commitment was found 
to have positive relationship with network performance (Clarke, 2006). Normative commitment can be defined that the individual commits to and remains with an organization because of feelings of obligations. Normative commitment was found to have significant effect on job performance of employees (Riaz \& Zia, 2005). According to Ozag (2002) there was a statistically significant association found between perception of trust and normative commitment. There was a positive relationship found between normative commitment and the perception of trust and hope for survivors of mergers (Ozag, 2006). Normative commitment was found to have significant effect on performance of employees (Clarke, 2006).

From the above discussion of organizational commitment the following hypothesis can be derived.

$\mathrm{H}_{1}$ : Organizational commitment has significant impact on organizational citizenship behavior.

\section{Job Satisfaction (JS)}

The employees with high age have low perceived of job loss and Job Satisfaction is high compared to low age employees, there is a positive link of Education with Job Security as it leads to Job Satisfaction (Theodossioua \& Vasileiouc, 2007). The changes in organizational variables i.e. pay scales, employee input in policy development, and work environment could be made to increase organizational commitment which in turn will lead to employee commitment and satisfaction (Hnif \& Kamal, 2009). Job satisfaction of bank officers is significantly dependent upon pay, promotion opportunities, rewards, relation with boss and coworkers. It is evident that the dependent variable satisfaction with pay has the expected positive effect on job satisfaction. Workers dissatisfied with their bosses are more sensitive to their pay. Gupta and Josh (2008)have reported that Job satisfaction of employees can be judged through the system of pay and monitory benefits that affect the Job satisfaction of employees.

The research of Ali (2005) has found that the management of colleges must focus on four facets of Job Satisfaction i.e. pay, promotion, contingent rewards and fringe benefits to increase the satisfaction level of College lecturers and bring down turnover intention. Presently lecturers have high level of turnover intention (4.051) means that likely to leave the organization. According to the study of Dickson and Lorenz (2009), organizational tenure of a temporary or part time nonstandard worker is positively associated with Job Satisfaction. In addition to this, two of the four cognitions of psychological empowerment (meaning and impact) are positively associated with job satisfaction. The results have implications for the managers of nonstandard workers and proper training to be provided to supervisors so that they can maximize the level 
of psychological empowerment and job satisfaction of employees with this increasingly common type of organizational relationship, since improving the productivity and retention of these workers may have a significant impact on the performance of a supervisor's workgroup and even the organization as a whole.

The study of Tutuncu and Kozak (2007) have concluded that there is a positive relationship among all the factor attributes whereas the level of overall job satisfaction was the strongest predictor of the intention to continue working in the hotel business, followed by supervision, payment and co-workers. Graaf-Zijl (2008) has explored positive relationship between contingent work arrangements and job satisfaction. Bhandari and Heshmati (2006) have found in their study that a substantial wage gap exists between permanent and contractual workers where contractual worker earn $45.5 \%$ less than their counterpart.

$\mathrm{H}_{2}$; Job satisfaction has significant impact on organizational citizenship behavior.

\section{Methodology}

The population for this study was the sub-contractual employees of Twin Cities (Rawalpindi and Islamabad). Since these sub-contractual employees have not been focused so that was the reason for selecting these employees. In twin cities there are many sub-contracting organizations who provide sub contractual employees to the respective organizations in other words with whom they have contract. Three organizations were selected on the basis on convenience to the researcher. These organizations are Human Resource Solutions International (HRSI). Currently HRSI has around 170 sub contractual employees working under their contract in different organizations. Human Resource Solutions Global (HRSG). The current numbers of employees under the contract of HRSG are around 168 employed in different organizations. United Human Resource Solutions (UHRS) is the third organization that provides sub contractual employees. Currently UHRS has approximately 173 sub contractual employees under their contract. So for these three sub-contracting organizations the total number of employees was 511 which also constituted the population for the study in respect to these three organizations.

The sample size consisted of 300 sub contractual employees. 300 questionnaires were distributed in the sub-contractual organizations 100 to each organization i.e. Human Resources Solution International (HRSI), Human Resources Solutions Global (HRSG) and United Human Resource Solutions (UHRS). The returned questionnaires were 223 having the response rate was $74.3 \%$ overall. Out of the 223 questionnaires returned on individual organizational basis 83 were from HRSI having response rate of $83 \%, 77$ were from HRSG having response rate of $77 \%$ and 63 were 
returned from UHRS having response rate of $63 \%$. Two different tested questionnaires were used in this study for Organizational Citizenship Behavior (OCB) and Organizational Commitment (OC) separately.

The questionnaire for this study was divided into three sections. Section 1 was related to the Organizational Citizenship Behavior and its measures, Section 2 was related to the Organizational Commitment and its measures and job satisfaction and its measures Section 3 was related to Demographic characteristics. The questionnaire that has been used for this study is mentioned at the en $\mathrm{d}$ in the appendix. OCB Items have been taken from the measure developed by (Podsakoff, Mackenzie, Moorman and Fitter (1990); (Podsakoff, P.M., Mackenzie, S.B., Moorman, R.H., Fitter, R. (1990)). OC Items have been taken from the measure developed by (Allen and Mayer, 1990a; Cohen 1996;1999; Cohen and Kirchmeyer, 1965; Hackett et al, 1994; Mayer and Allen, 1997; Mayer, Irving and Allen, 1998; Somers and Bimbaun, 1998). For job satisfaction the scale developed by Cook, J.D., Hepworth, S. F., Wall, T.D. and Warr, P.B (1981) was used.

\section{Results}

From the above table of reliability statistics it is evident that Altruism had five items for measurement and the Cronbach's alpha value is 0.920 . This represents

Table 1: Reliability Statistics

\begin{tabular}{|l|c|c|}
\hline \multicolumn{1}{|c|}{ Variables } & Cronbach's Alpha & N of Items \\
\hline Altruism & .920 & 5 \\
\hline Courtesy & .893 & 5 \\
\hline Sportsmanship & .793 & 3 \\
\hline Affective Commitment & .871 & 5 \\
\hline Continuance Commitment & .875 & 5 \\
\hline Normative Commitment & .849 & 5 \\
\hline Job Satisfaction & .784 & 6 \\
\hline
\end{tabular}

the high reliability of the items that measure Altruism. So this measure is highly reliable. Courtesy had five items for measurement and the Cronbach's Alpha value is 0.895 . This represents that the items are high reliable and measuring the measure Conscientiousness. So this measure is highly reliable. Sportsmanship had three items for measurement and the Cronbach's Alpha value is 0.793 . This represents that the items are high reliable and measuring the measure Sportsmanship. So this measure is highly reliable. The Cronbach's Value 0.894 represents high reliability of the measure Affective Commitment. So the measure (Affective Commitment) is highly reliable. 
The Cronbach's Value 0.876 represents high reliability of the measure Continuance Commitment. So the measure (Continuance Commitment) is highly reliable. The Cronbach's Value 0.849 represents high reliability of the measure Normative Commitment. So the measure (Normative Commitment) is highly reliable.

The above table 2 of descriptive statistics of Independent Variable (OC) and (JS) and Dependent Variable (OCB) states that the mean values of all the variables included

Table 2: Descriptive Statistics OCB, OC and JS

\begin{tabular}{|l|c|c|c|}
\hline & Mean & S.D & N \\
\hline OCB & 3.28 & .89 & 223 \\
\hline OC & 3.19 & .97 & 223 \\
\hline JS & 3.35 & .78 & 223 \\
\hline
\end{tabular}

in the study. Since the response scale was five point lickert scale so the mean value 3.28 with Standard Deviation 0.89 of OCB indicates that the response is above mean and reflects that the responses are on positive side and the mean value 3.19 with Standard Deviation 0.97 of $\mathrm{OC}$ indicates that the response is above mean and reflects that the responses are on positive side and the mean value 3.35with Standard Deviation 0.78 of JS indicates that the response is above mean and reflects that the responses are on positive side. The sample size was 223.

The above table 4 shows the Model Summary of Independent Variable (OC) and

Table 3: Regression Statistics

\begin{tabular}{|l|c|c|c|}
\hline Model & Variables Entered & Variables Removed & Method \\
\hline 1 & OCBa &. & Enter \\
\hline
\end{tabular}

a. All requested variable entered

b. Dependent variable $\mathrm{OCB}$

Table 4: Model Summary OC - OCB

\begin{tabular}{|c|c|c|c|c|c|c|c|}
\hline \multirow[b]{2}{*}{ Model } & \multirow[b]{2}{*}{$\mathrm{R}$} & \multirow[b]{2}{*}{ R Square } & \multirow[b]{2}{*}{$\begin{array}{l}\text { Adjusted } \\
\text { R Square }\end{array}$} & \multirow{2}{*}{$\begin{array}{l}\text { Std. Error } \\
\text { of the } \\
\text { Estimate }\end{array}$} & \multicolumn{3}{|c|}{ Change Statistics } \\
\hline & & & & & $\begin{array}{l}\text { R Square } \\
\text { Change }\end{array}$ & F Change & $\begin{array}{c}\text { Sig. F } \\
\text { Change }\end{array}$ \\
\hline 1 & $.636 a$ & .404 & .402 & .68466 & .404 & 150.105 & .000 \\
\hline 2 & .563 & .543 & .539 & .56674 & .563 & 134.546 & .000 \\
\hline
\end{tabular}

a. Predictors (constant), OC

b. Dependent variable OCB 
Dependent Variable (OCB). The value of $\mathrm{R} .636$ indicates the correlation between the $\mathrm{OCB}$ and $\mathrm{OC}$. The correlation Value is $63.6 \%$ that indicates that there is strong correlation between these two variables. The value of $\mathrm{R}$ square .404 represents that $40.4 \%$ variance in dependent variable is explained by $O C$. There are other variables also that were taken in this study, that contribute or explain the variance in the dependent variable. The value of $\mathrm{F}$ change 150.105 with the significance level .000 represents the highly significant result. Since the standard value of $\mathrm{F}$ at $5 \%$ is 3.78 so higher value of $\mathrm{F}$ shows highly statistically significant Results. For JS being the independent variable and $O C B$ being dependent variable. The value of $\mathrm{R} .563$ indicates the correlation between the OCB and JS The correlation Value is $56.3 \%$ that indicates that there is strong correlation between these two variables. The value of $\mathrm{R}$ square .543 represents that $54.3 \%$ variance in dependent variable is explained by JS. There are other variables also that were taken in this study, that contribute or explain the variance in the dependent variable. The value of $\mathrm{F}$ change 134.546 with the significance level .000 represents the highly significant result. Since the standard value of $\mathrm{F}$ at $5 \%$ is 3.78 so higher value of $\mathrm{F}$ shows highly statistically significant Results.

From the above table 5 of coefficient the Beta value is 0.573 . $\beta$ value represents

Table 5: Regression of the predictor variable OC JS and criterion variable OCB

\begin{tabular}{|c|c|c|c|c|c|c|}
\hline \multicolumn{2}{|c|}{ Model } & \multicolumn{2}{|l|}{$\begin{array}{l}\text { Unstandardized Co- } \\
\text { efficients }\end{array}$} & $\begin{array}{c}\text { Standardized } \\
\text { Coefficients }\end{array}$ & \multirow{2}{*}{ Sig. } & \\
\cline { 3 - 6 } & B & $\begin{array}{c}\text { Std. } \\
\text { Error }\end{array}$ & Beta & & \\
\hline \multirow{2}{*}{1} & Constant & 1.313 & .160 & & 8.232 & .000 \\
& OC & .573 & .047 & .636 & 12.252 & .000 \\
\hline 2 & JS & .653 & .036 & .689 & 9.435 & .000 \\
\hline
\end{tabular}

the change in the independent variable. The $t$ statistics are calculated to decide on the rejection or acceptance of hypothesis. This acceptance or rejection is decided on the basis of $\mathrm{p}$ value. The $\mathrm{t}$ value is $12.252(\mathrm{P}<.05)$ with the significance level .000 , it states that on the basis $\mathrm{H}_{1}$ is accepted. It shows that the result is highly significant. So the hypothesis $\mathrm{H}_{1}$ i.e. Organizational Commitment has positive and significant impact on $\mathrm{OCB}$ and strongly determined the $\mathrm{OCB}$. The Beta value is 0.653 . $\beta$ value represents the change in the independent variable. The $t$ statistics are calculated to decide on the rejection or acceptance of hypothesis. This acceptance or rejection is decided on the basis of $\mathrm{p}$ value. The $\mathrm{t}$ value is $9,435(\mathrm{P}<.05)$ with the significance level .000 , it states that on the basis $\mathrm{H}_{2}$ is accepted. It shows that the result is highly 
significant. So the hypothesis $\mathrm{H}_{2}$ i.e. job satisfaction has positive and significant impact on $\mathrm{OCB}$ and strongly determined the OCB.

\section{Conclusion}

The aim of this research was to find out the impact of organizational commitment and job satisfaction on organizational citizenship behavior and also the effect would reflect that whether these two independent variables could be treated as the determinants of $\mathrm{OCB}$ or not. The results of the study showed that organizational commitment was found to have significant impact on organizational citizenship behavior and thus hypothesis $\mathrm{H}_{1}$ was accepted with the truth that organizational commitment strongly determined the organizational citizenship behavior. The other independent variable was the job satisfaction. The results of the study showed that job satisfaction was found to have significant impact on organizational citizenship behavior, so hypothesis $\mathrm{H}_{2}$ was accepted with the truth that job satisfaction also served as the determinants of organizational citizenship behavior. At last it can be concluded that more employees stay committed with their organization higher will be their inclination towards citizenship behavior and at the same time the more employees are satisfied again higher will be their inclination towards citizenship behavior.

\section{Limitations and Future Research Directions}

Although it has been tried to make the study comprehensive enough but still the study is with some limitations as discussed below. Conducting a country wide research was not feasible that is why the research was limited to Twin Cities (Rawalpindi $\&$ Islamabad). The sample size is also a limitation it can be increased in suitable circumstances by collecting data from more subcontracting organizations. It was a cross sectional study whereas a longitudinal study can give improved results. In future the researchers should try to extract results with increased data collection from more organization of subcontracted nature. In future the researcher should try to expand the span of research on the same topic to other cities of the Pakistan as well, for the purpose to get more insight into the citizenship behavior of subcontracted organizations.

\section{References}

Ali, N. (2005). Factors Affecting Overall Job Satisfaction and Turnover Intention.

Bhal, T. K. (2006). LMX-citizenship behavior relationship: justice as a mediator. Leadership and Organizational development Journal, Vol 27.

Bhandari, K. A. \& Heshmati, A. (2006). Wage Inequality and Job Insecurity among Permanent and 
Contract Workers in India: Evidence from Organized Manufacturing Industries.

Bukhari, Z., Bashir, S., Ali, U., \& Shahzad, K. (2009). Determinants of Organizational Citizenship Behavior in Pakistan. International Review of Business Research Papers.

Dickson, E. K. \& Lorenz, A. (2009). Psychological Empowerment and Job Satisfaction of Temporary and Part-Time Nonstandard Workers: A Preliminary Investigation. Institute of Behavioral and Applied Management.

Graaf-Zijl, D. M. (2008). The relationship between job satisfaction and contingent employment.

Gupta, A., and Joshi, M. (2008). A satisfied employee is a productive employec.

Hanif, F. M. \& Kamal, Y. (2009). Pay and Job Satisfaction: A Comparative Analysis of Different Pakistani Commercial Banks.

Kharti, N., \& Fern, C.T. (2001). Explaining employee turnover in an Asian Context. Human Resource Management Journal, Vol 11.

Organ, D. W. (1988). O.C.B: The Good Soldier Syndrome. Lexington, MA.

Organ, D. W. (1990). The motivational basis of organizational citizenship behavior. Research in Organizational Behavior. 